\section{DSRRC SciencePark Research, Organization \& Counseling \\ International Journal of Learning and Teaching}

Volume 09, Issue 3, (2017) 354-363

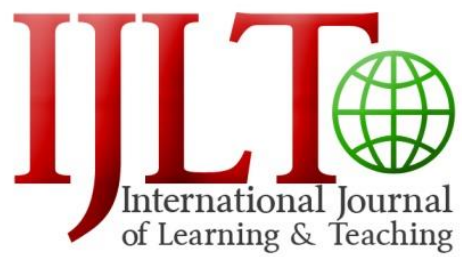

www.ij-It.eu

\title{
The Influence of existentialism on teaching methods
}

Davood Yahyaei*, Department of Educational Sciences, Boushehr Branch, Islamic Azad University, 14515, Boushehr, Iran.

Fakhteh Mahini, Department of Educational Sciences, Boushehr Branch, Islamic Azad University, 14515, Boushehr, Iran.

\section{Suggested Citation}

Mahini, F. \& Yahyaei, D. (2017). The Influence of existentialism on teaching methods. International Journal of Learning and Teaching. 9(3), 354-363.

Received February 27, 2017; revised May 10, 2017; accepted July 5, 2017.

Selection and peer review under responsibility of Prof. Dr. Hafize Keser, Ankara University, Ankara, Turkey. ${ }^{\circledR} 2017$ SciencePark Research, Organization \& Counseling. All rights reserved.

\begin{abstract}
Existential theories and Humanistic psychology are widely used in education. According to existentialists, fundamental problem of philosophy is Valuation and choice. Making existential methods in the classroom requires a balance in which both teachers and students as human beings preserve its identity. Existentialist philosopher and humanist psychologists advocate the kind of teaching and learning methods that focus on the learner and Care about individual differences. The research objective was identifying the teaching methods and the characteristics of each one supported by this approach. This research was done using qualitative content analysis and reviewing literature on the subject was published. The method of data analysis was thematic coding by using deductive category application. The results showed that the existentialists emphasized on the relation "I - you" between teacher and student thus support the teaching methods that consider individual patterns and indirect instructions. These methods cause growth of efficient relations and positive selfconcept. Such methods are dialogue; Learner-centered method and developing positive self-concept. Existential education goals cannot be predetermined and cannot the teacher and the educational system impose to students. Everyone assumes responsibility for its education. So, the teaching methods which develop concepts related to individual growth or focus on the learner are supported by this sect.
\end{abstract}

Keywords: Existentialism, existential Education, dialogue, Learner-centered method, positive self-concept.

\footnotetext{
*ADDRESS FOR CORRESPONDENCE: Davood Yahyaei*, Department of Educational Sciences, Boushehr Branch, Islamic Azad University, 14515, Boushehr, Iran.

E-mail address: DYahyaei@yahoo.com / Tel.: +989177734781
} 


\section{Introduction}

Existentialism can be considered as a type of philosophical mentality which emphasizes the individual's uniqueness and freedom against a group, population, or mass society and relies on the point that all people are thoroughly responsible for the meaning and concept of their own life and they are responsible for creating the nature or definition of their identity. They try to encourage and simplify individual's learning and understanding in existentialistic teaching. Creating existentialistic ways and methods in class requires realizing an elegant balance in which the teacher preserves his/ her identity as well as the student. This means the teacher must avoid getting pulled into a situation where the students are simply defined based on their age, education, honor, or being a group member. With one such view, existentialist philosophers and humanistic psychologists appreciate teaching and learning methods which make the learner the center of attention and consider the individual differences as important. Therefore teaching methods such as dialogue method, the learner in the center, and individual growth and development view are the best educational instruments for this view.

\section{Philosophy of Existentialism}

This school became very popular in the twentieth century, especially during the Second World War and after that. "Existentialism" was a simple title which has been given to a set of completely different mutinies against traditional philosophies especially against efforts which were made to create orderly and abstract thinking systems. Existentialism could be considered as a sort of philosophical thinking which emphasizes the individual's uniqueness and freedom in groups, populations, or mass societies and relies on the point that all people are thoroughly responsible for the meaning and concept of their own life and they are responsible for creating the nature or definition of their identity (Gutek, 2005).

The roots of this thinking system could be found in sophists. This philosophy began in the $19^{\text {th }}$ century with Kierkegaard and Nietzsche's works and Buber, Jaspers, and Sartre developed it in the twentieth century. Existentialism became more popular when the books "Being and Time" by Heidegger and "Being and Nothingness" by Sartre were published in 1927 and 1943. These books made the philosophy turn to studying the specific human from studying an abstract existence which means human was studied in his daily life on the one hand and regarding his relationship with others on the other hand (Shoarinejad, 2004).

The existentialist school led to an upheaval in psychology as well an upheaval entitled humanistic psychology which included a set of obligations for educational psychology and learning theory and consulting psychology. Rollo May, Viktor Frankl, Abraham Maslow, Gordon Allport, and Carl Rogers are amongst humanistic psychologists (Gutek, 2005).

\section{Principles of Existentialism Philosophy}

Absolute freedom and human being responsible for his decisions are the repeated concepts of existentialism. In contrast with Aristotle's claim which stated that human is a rational being in nature and lives in a purposeful and meaningful world, Jean- Paul Sartre, an existentialist philosopher, claimed that each person exists first and then he/ she creates his/ her meaning and nature. Because there are no general truths, absolute laws, or a final destiny which guides humans, individuals are absolutely free to choose. This absolute freedom requires human's thorough responsibility for his actions and decisions (Gutek, 2005).

Understanding reality- the fundamental principle of existentialism, which is based on existence proceeding essence, explains the human subjectivity being the priority. Man enters the world first and then begins his efforts to understand himself. This consciousness makes human develop his essence through individual, personal, and mental selectivity. Each person is obligated to create the goal of his own life. Existentialists believe that the fundamental philosophical problem is the matter of valuing and selecting (Gutek, 2005). Existentialism tries to identify the human existence and his 
paradoxes and the origin of these paradoxes and it tries to predict the manner of dominating them and it values self- discovery (Shoarinejad, 2004).

From this school's view, the world is constant, unchangeable, and an impersonal environment which human must accept and live in. while human lives in an impersonal, constant environment he is a creature who begins his life upon his own decision. Which means the world we are forced to live in also gives us the right to choose and it gives this right to everyone. T power to select and mental awareness is human's specification and human is responsible for the decisions he makes and his freedom is what separates him from other beings and this freedom is the product of human awareness.

From the existentialism's viewpoint, the material world or the universe minus human, has no meaning and no objective. This world is a probable affair, a thing which happens to exist. This does not mean that the world is based on temptations. The systems and rules discovered by science are original enough however, they lack direct human meanings. They do not match any of the human tendencies or ideals if they are understood right, except for the tendency to be safe which includes the tendency to get rid of real freedom and real fear of human condition. Human exists in this world by accident. There is no universal order or a natural design for objects where human has been created in as well. Therefore the only thing human owes nature is his existence. Therefore his existence proceeds his essence which means if human is to be something, he must exist. But existence does not form human. He forms himself while he exists. The main and fundamental motivation of each individual includes existing and being discovered. Life finds its meaning and importance through that and the meaningful reference for each person is his own instant understanding or intelligence (Shoarinejad, 2004).

Axiology- existentialism believes that values are not absolute and they have not been determined by foreign criteria but every value is determined through the free choice of the individual. The fundamental value for each person is his being or existence. Important values of each person depends on the conditions and they are relative and in short, value is completely personal (Soarinejad, 2004). Existentialists believe that the fundamental philosophical issue is setting values and choosing. Values are not stemmed from metaphysical assumptions or real historical sociology, they are created by personal decisions.

Epistemology- followers of existentialism believe that a person obtains wisdom while experiencing. Although experiencing has different levels, the individual obtains the highest level of experience which is the "awareness" level through becoming aware of the existence of the objects and beings, the way they are. Reality always depends on the individual's judgment and it is relative. There are no absolute facts and each person must vote for what reality is and what is important for him/ her (Shoarinejad, 2004).

The traditional educational philosophies and the institutional performances based on them emphasize developing the mental dimension of human as the major educational efficiency. In contrast with these philosophies, existentialism considers human less carefully but more varied. Human is rational as well as an irrational being in that unit: he is thoughtful and cognitive as well as emotional (Gutek, 2005).

The existentialistic epistemology assumption is that the individual is responsible for his own knowledge and wisdom. Wisdom stems from the individual's awareness and is formed from the awareness and emotions content as the product of experience. Authenticity turns wisdom to value and determines its meaning for a specific individual. While pragmatists emphasize the application of problem- solving scientific method, the existentialists prefer to examine aesthetical, ethical, and emotional issues of human as well as the cognitive affairs (Gutek, 2005).

The major part of the existentialist philosophy's mentality about the nature of understanding is the field of phenomenology. Phenomenology is a sort of worldview which tries to define the appearance of objects and events in such a manner that they directly present themselves to our personal consciousness. Therefore these phenomena have subjective and objective reality. Objective reality means direct and personal associations which we all find with nature (Naler, 1998). Reality begins when we no longer live in terms of objective evidence and we have understood the fundamental mentality of all our experiences as an inseparable part of reality. Therefore we must 
rethink the concept we hold about wisdom. The syllabi and documented knowledge must not be considered as objectives by themselves or an instrument to prepare the individual for getting a job but they must be considered as self- realization or progress tools. Content must follow the individual and the individual must dedicate whatever he learns to himself and must make that knowledge his. Subjects must turn into tools for self- realization. The developing individual must think about facts for himself and not facts as abstracts but his own facts. This does not mean that he believes whatever he wants but he must think about them being accurate and discuss it (Naler, 1998).

\section{Humanistic Psychology}

Humanistic psychology which is also called the third force in psychology was created in the 1950s and the beginning of the 1960s by Maslow and Rogers. This viewpoint, which is comprehensiveoriented, has considered human realization as important and gives originality to children through curriculum and gives more weight to the emotional aspects of children and excites intrinsic motivation in students (Vajargah, 2001).

Rogers who invented the "client- centered" concept, insists what the individual must create the concept of reality and self- concept himself. The meaning of this process of creating a personal identity is that the person exists. In other words the person is located in the center of a dynamic experimental world which although includes social interactions, it is eventually a private affair. The face of self or the personal identity will appear as a result of social and environmental interactions however this personality is the accomplishment of the individual himself and represents the flourishing of his own personality and it is not the results of other people's work. Existentialistic teaching tries to encourage and simplify learning or self- evaluation and personal recognition in the general meaning of the world. Creating existentialistic ways and methods in class requires realizing an elegant balance in which the teacher preserves his/ her identity as well as the student. This means the teacher must avoid getting pulled into a situation where the students are simply defined based on their age, education, honor, or being a group member. Another meaning of this is that the learners must also be aware of the fact that they could also define the teacher not as a person but as an agent who has supervising, educational, and monitoring responsible (Gutek, 2005).

\section{Existentialistic Education}

This school considers personal experiences and the child's pure and direct reactions as his/ her educational axis and the unique individuality of the child is the central point of education. The teacher and the students have different experiences and it is the teacher's duty to use the students' experiences as the basis and axis of his own work. Education must awaken the individual's awareness and this awareness is related to awareness of one's own existence which is present in the world (Shoarinejad, 2004). The efforts of existentialistic education include training the original person who is aware of freedom and that each decision contains personal value creation (Gutek, 2005).

The objectives of a socialized education includes affairs such as learning to cooperate with others, successful performance in group situations and working as an efficient member of the team or group. According to group- centered educational theories, the individual becomes more effective and efficient through simulation and group cooperation. Existentialist teachers act cautiously when it comes to glorifying groups since they believe that some group situations frustrate the individual to an extent to which there is a fear of them sacrificing their personal originality because of the pressure to be the same. There are still rooms for original decision when the individual freely chooses to join a group and work in it. Despite that many group- oriented school situations are not selected freely. In any case, the learning situations which are organized around the axis of group must be in such a manner that they provide opportunities for individuals to exhibit the unique aspects of their personality (Gutek, 2005).

Moris believes that education must lead to intensity of awareness in the learner. This awareness means that the students must understand that he constantly, freely, independently, and creatively makes decisions as a person. This awareness includes the person's responsibility towards the manner of his own life and the manner of creating his own personal individuality. Existentialistic educational 
psychology identifies two growth periods for human: the pre-existing period and the existing moment. During the first period, the child who is really unaware of his human conditions is not aware of his personal identity and his destiny. The pre-existing years are simultaneous with the primary education period. The period is where the children learn reading, writing and counting and physical, recreational, relationship and social skills. Children also learn a little of the program content and some problem- solving skills in addition to that. But the existing point appears when individuals become aware of their presence in the world as "me". This realization commonly occurs around physical puberty and its properties include the individual becoming aware of his presence in the world and the appearance of insight in him regarding his awareness and responsibility towards his actions. Therefore existentialistic education begins from the junior high school and continues to high school years and the four- year university period. The aim of one such education is to awaken and intensify the individual's self- awareness. Existentialistic education considers elements of experience which are mental, personal, and emotional and encourages human to face situations which guide him towards this understanding that human's decisions require posing a personal question about good and bad and right and wrong (Gutek, 2005).

Specialized education must progress together with humanity education and specialty must absorb humanity aspect as much as possible. Human must govern his specialty not be a slave to it. Education must be about experiences which make the individual more aware of human states and conditions such as suffering, conflict, sin, and death which provide understanding. We cannot get away from this condition we must try to understand them and face them wisely (Naler, 1998).

Open education is in fact a reaction to overt emphasis on mental and cognitive learning in schools. The development of the concept of "self", personal growth, and students' emotions and expression are promoted and encourages in this type of education. The students are taught to always be constructive, adapt themselves to the environments and not to follow the rigid rules of the school (Fathi Vajargah, 2009).

The basic direction of this theory is utilizing human's potential abilities for growth and selfactualization. Learning experiences must provide the grounds for cognitive and emotional involvement of students. Therefore conceptual learning is integrated with emotional growth. From Gerald Weinstein's viewpoint, the five criteria for designing humanistic curriculums include:

1- The individuals' essentials, the most important information resource for decision- making.

2- Humanistic education, increases the learners' right to choose

3- Personal knowledge, is at least as important as general knowledge

4- An individual's growth does not prevent another individual from growing

5- All the elements of the curriculum must help the sense of being important and being valuable in other people's work.

Two basic dimensions this view focuses on are a- attending to the children's interests, needs, and issues (influenced by child psychology) b- attending to values system, psychological health, and learner's freedom in learning (consequence of humanistic psychology).

Aim of education- the major objective of training is to serve human. Training must help humans find true and essential awareness of them. The important and specific existentialistic education includes: growth and development of individual awareness, providing ethical and free decisionmaking opportunities, encouraging self- discovery and growth and development of personal responsibility or training responsible individuals.

Curriculum includes skills and topics which explain social and natural realities and most importantly it includes humanities which explain human's choice. Topics such as history, literature, language, mathematics, science, and etc. are considered definite wisdom fields. The essential stage of learning is imbedded in the meaning the student makes not in the structure of wisdom or the curriculum organization (Gutek, 2005).

There are different views regarding curriculum which existentialism supports from the selfactualization or personal relationship viewpoint. This standpoint is based on the priority of the matter of the curriculum being meaningful to the learner and the responsibility of the school towards arranging and executing programs which are in accordance and adaptable to this priority. In other 
words, the individual is the axis and the program- decision- making and information resource. Teachers must prepare their educational programs through arranging with students and their consultation in schools. Executing predetermined plan is not advisable at all since in case the plan is designed and executed in a concentrated manner it would definitely not be based on carefully identifying the needs and interests of the students and their varied conditions. In a "teacherstudent" design where the curriculum is generated from friendly action and reaction between the teacher and the student, the educational experiences will only be educational for the individual and the materials will only be sustained and retained when the student is part of designing and executing it. It is only the active cooperation of the student in designing the educational experience or experiences and the learning activities which can act as guarantees for real learning. The student must therefore have the right to choose and make decisions and must be able to have a share in designing the plans and activities in which he is going to get involved with.

Based on this view, since human is a creature that "searches for stimulus" and has no need for external factors in order to be encouraged to learn, the school's duty and responsibility is to provide a rich environment regarding resources in which case the students will use their innate motivation to learn without utilizing encouraging and stimulating mechanisms (Mehrmohammadi et al. 2009).

The teacher's role- the teacher must look at each and every one of the learners from an individualistic viewpoint and the features they may have that distinguishes them from others. Moreover, the teacher must be able to create a very close human and emotional relationship with the students. Through that the teacher could understand what is going on inside a student's mind, what he/ she has experienced and learned and what is his/ her view about the things he/ she has learned. The teacher is the person who provides proper educational resources and environment and guides his students without prescribing or imposing anything. In other words, the teacher stimulates, encourages, and guides. The students' assignments and duties are determined based on the interaction between the students and the teacher (Mehrmohammadi et al. 2009). The teacher is only the facilitator and a partner who moves forward with the student every step of the way but does not tell the student what to or what not to do.

The teacher has a role in forming the atmosphere governing the class. The teacher presents the students with a proper model for exploiting communication skills through active listening; the teacher welcomes new ideas and so he is also a learner; he helps the learner be independent and responsible through allowing free speech and letting the learner pose open questions and obtain positive and good feelings about his learning experiences. The teacher must be able to create good human and emotional relationship with the students and be honest about his feelings and emotions and he must not impose his wills and tendencies on the students. Although we could not expect students to learn a lot of things through this method, the important matter is that they will learn how to learn.

The learner's role- the learner capable of self- leading and self- evaluation and takes responsibility for his own learning. He has an active, spontaneous, responsible, innovative, creative, critical and decisive individuality and is capable of adapting himself to conditions with new problems. The learners benefits from useful learning experiences when he participates in the education process. These experiences match their interests, facilities, needs, and their developmental assignments (Maleki, 2001).

Is proper facilitating conditions are provided the students are able to develop their potential capabilities. The student is affected by his own emotions and lives with the present moment.

The number of students must much fewer than usual in schools. There must be almost 15 students with different ages in each class. The basis for dividing the students and placing them in different classes must be their skills' needs, and interests (Mehrmohammadi et al. 2009).

Curriculum- existentialism does not agree with being topic- centered, the student must be the main axis and what he needs must be included in the curriculum. This curriculum emphasizes the following issues: the curriculum being active, the students being interested in the basic title of the plan and activity, students being absolutely free to choose to work in a group or by themselves, establishing the curriculum based on instant and direct needs, identifying the individual differences in the experiences (Shoarinejad, 2004). 
The curriculum comes out of the teacher- student interaction. It is not presented to the student in a pre- determined manner. In other words, the curriculum originates from friendly action and reaction of the teacher and the student which forms a planning process known as teacher- student (Maleki, 2001).

No subject is more important than the other subject. The subject through which the individual realizes himself and becomes aware of the universe is considered an important subject. This subject is that same natural science or history, literature, art, and philosophy. The individual becomes familiar with the scientific accomplishments of great scholars and authors regarding the nature of human in the world, freedom, sin, suffering, conflict, success, and death through this subject which means topics which the individual must get mentally and emotionally involved with. For instance, history is human's battle for realizing his freedom (Naler, 1998).

Learning environment- the classrooms are free, they are environments filled with trust, mutual respect, cooperation, and friendship in such a manner that the student can share his feelings with others (Mehrmohammadi, 2009). The learning environment is a large class with a flexible atmosphere where the walls and chards can move and the teacher's place is not fixed; a rich environment regarding resources, in such a manner that the student can discover his skills based on his interests and talents; there is a warm, positive, and welcoming atmosphere and the student feels like he can learn; the learning atmosphere is in such a manner that it encourages individual growth and an ongoing learning process is emphasized (Biyabangard, 2005).

The content and organizing it- interest and motivation are the basic and key criteria in learnercentered plans. These criteria must be included in the content. The emotional aspects are more important that the cognitive aspects; meaningful experiences for the learners must be included in the content. The content must help the individual gain a correct understanding of his own identity and to gain meaning and useful application; it should be able to attend to individual differences and comprehensive experiences and make the child curious and create inner pleasure for the child. Properly organizing the content and its sequence must lead to learning capability therefore the content must be organized in such a manner that it takes the learner higher.

Assessment- self- assessment could be the best type of assessment. The teacher controls the assessment through the student assessing himself while learning with an honest feedback. Testing and scoring is useless. A degree indicates the end of the result but the learner is interested in continuing the learning process (Biyabangard, 2005).

It is better if scoring is not the only assessing resource in the primary course and for friendship spirit to be used instead of competitive spirit.

\section{Existentialistic learning and teaching methods}

Teaching method is closely related to the objectives and goals of the curriculum and indicates the learning and teaching processes during which the learner becomes familiar with special knowledge and skills included in the curriculum. Learning and teaching methods have the closest relationship with epistemology or the cognitive theory or the method for thinking correctly. Studying education leads to obtaining signs about learning approaches which is related to a concept of cognition which is a component of the philosophical system (Gutek, 2005).

The existentialism philosophy became popular simultaneously with the appearance of dissatisfaction with optimistic viewpoints of science, technology, and progress in the nineteenth century. This anxiety has become worse due to the development of mass society, which has impersonalized the individual, since the appearance of mass society has made alienation more intense. Existentialists intent to decrease the relationship impersonalization phenomenon which has affected the educational system of the twentieth century and they intend to emphasize the relationship "me- you" between the teacher and the learner. Therefore they see themselves as being a part of a public obligation regarding changing the condition of humans in order to flourish the manifestations of the human personality more freely and originally (Gutek, 2005).

Although the existentialist instructor may select varied educational methods for his work, none of them must interrupt the "me- you" relationship which must exist between the teacher and the student (Gutek, 2005). The existentialist teacher mist use indirect and democratic technique and method in his teaching. The teacher never imposes his personal objectives to the students in a 
democratic method and the duty of the teacher is to guide. The teacher schedules his plans based on the personal objectives and needs of the students and through their help. The teacher must also avoid forcing and imposing learning and must indirectly provide opportunities and chances to excite the students' learning for them to be active voluntarily (Shoarinejad, 2004).

Therefore the schools and teacher's responsibility is to create an environment where learnercentered learning flows; active methods must be used (involve the learner in the learning process) in such a manner that each person can have an effective role in learning based on his own learning knowledge and information. Individual models are used and the teacher encourages the learner to express his feelings; the problem is presented by the student and he obtains insight through discussing the matter and the teacher will support him (Joyce, Weil \& Calhoun, 2009).

Socratic conversation method is a suitable method for existentialist teachers. The existentialist teacher does not know the answer to the posed question in contrast with the idealistic teachers when using dialogue method. In fact the best type of question can only be answered through the student making it meaningful. The teacher's duty is to provide the learner with an opportunity to express their mentalities. It is only the teacher who can face attaining personal identity through his duty. The teacher and learner are equally responsible for intensifying awareness. This sort of awareness requires the feeling that the individual must tangle with the ethical and aesthetic aspects of existence in person (Gutek, 2005).

John Holt, one of the advocates of children's freedom and open education, has a practical approach to the existentialistic view in the school. He supports educational reforms which provide learning freedom for the child. He suggests "open-door class" as an environment which creates numerous opportunities for selecting in such a manner that the children learn through following their interests without the teacher or the school pressuring them. Hold supports spontaneous and self- assembling learning which is done by the students themselves. The teachers of open- door classes must create and promote opportunities for self- assembling learning. In contrast to the hardships of the traditional class which is often rigid, inflexible, and motionless, the open- door class is rich regarding carried learning opportunities. This sort of class has learning opportunities equal to the number of the teachers and learners in class. Learning in open- door class is unavoidable flexible and dynamic since different tendencies of the students are approved in there and their personal choices are supported and respected (Gutek, 2005).

Due to the ties in the official educational institutes, some existentialist instructors have focused on unofficial education outside schools which is free of formalities. For instance, Ivan Illich has defined the official education as an institutionalized process which has imprisoned the children and youths in specific institutes where they are obligated to be present full- time with teachers as their guardians and which forces them to finish an obligatory program. Illich introduces the "learning cores" or learning networks and points at participation based on free will which is intended by the existentialists which has a number of types:

1- The reference services network includes educational resources, objects, and tools

2- Educational transactions which have been designed for the purposes of providing training and special skills learning opportunities

3- Pairing up which makes finding individuals who want to participate in similar learning activities easier

4- Top scholars of education meaning the specialists who can act as consultants regarding specific educational matters

These cores or networks are realized outside the institutions and are used by the individuals for a duration they themselves determine without other people telling them what to do (Gutek, 2005).

Knowledge must not be transferred since the individuals will turn into objects and products in that case so it must be presented, Buber says that the teacher must completely familiarize himself with the subject he teaches and must absorb it into his being as a rich fruit of human activity. In that case he could present it to the students as part of his inner experience. Therefore the teacher and the student can face each other as two people since the knowledge the teacher represents is an aspect of the state and condition of his own existence (Naler, 1998). 
What occurs in that class, is students who have the right to choose and the student's feelings are presented. Personal and indirect education model is used which emphasizes self- concept growth and efficient relationships with the learners and the environment. Self- assessment and personal understanding is valued in education.

The effective teaching of the teacher is accompanied with the clear, responsible, kind, and mutual dependency and separation (each person must develop his own creativity) relationship between the teacher and the learner which meets the needs.

Some of the teaching methods which include being student-centered and attention to the particulars of each of them include: educational games method (especially in the primary course); common teaching method where the student learn as a group; using methods which are based on every- day experiences; filed trips, problem solving and participating, group games, art activities and theater games. Three widely used methods which are supported by this philosophical viewpoint will be explained below:

Dialogue method- the teacher presents different opinions to the class in order to provide the grounds for actual discussion about the content of the lesson. He has carefully studied the topic and presents the matter sufficiently in the class and asks each student to base this opinion on his/ her experience. The existentialist philosophy does not insist the teacher's success but he must be honest. In that case, the learners will trust him and they will see that the teacher's interpretations are wise. And so dialogue which is education will rely on inter- personal trust. This trust is formed through the correct behavior of the teacher and through skill. The teacher involves the student in the dialogue and encourages him to think. He asks the student questions about his thoughts, suggests other thoughts and so guides the student to select from amongst different ways. Therefore the student will understand that the reality does not happen to humans it is selected by them (Naler, 1998).

Learner- centered indirect method- this teaching model is based on Carl Rogers' writings and other advocates of indirect consulting. He believes that proper human relations makes the individuals ready for growth and development. Therefore education must be based on the concepts of human relations against the concepts of lesson topics or the thinking process. We use this method to consider the mental framework of the learners, to consider their development as axis and to help them solve their learning problems. The teacher has the role of the "facilitator" in this method who is the learner's consultant and guides their growth. The teacher helps the learners discover new theories about their own life and educational affairs and their relationships. The environment created in this method is open and the learners can talk about their issues freely and honestly with their teacher. The indirect teaching method focuses more on developing the personality of the learners than controlling the learning stages and emphasizes short- term educational or content objectives more than long- term learning methods. The teacher is a patient individual and does not sacrifice the vast long- term learning viewpoint for instant educational results (Joyce et al. 2009).

Method of developing a positive sense of self- not only can the learners learn the educational content and social skills in this method, they could also learn how to integrate their mind and learn the method of achieving the environment and interacting with it (Joyce, Weil \& Calhoun, 2009).

\section{Conclusion}

In contrast with orderly worldviews which have been presented by the traditional philosophies, existentialism tries to free humans from the world's categorized imitations. Existentialism which emphasizes human mentality, individual freedom, and personal responsibility, boldly defines human as an individual who is solely responsible for identifying himself in the field of his life. In their efforts to reach originally, people must figure out that they create their essence and values without using outside criteria. Existentialistic education considered human freedom as its most important duty. The existentialist trainer emphasizes the mentality of the individual and tries to promote self- awareness and a sense of responsibility in the students. Through personal meaningful choices, the learners can create their own personality by themselves. The objectives of this sort of education cannot be predetermined and the teacher and the educational system cannot impose it on the students. Each person is responsible for his own education. Based on that, teaching methods which can develop 
Mahini, F. \& Yahyaei, D. (2017). The Influence of existentialism on teaching methods. International Journal of Learning and Teaching. 9(3), 354-363.

concepts related to individual growth or can make the learner the center of the teacher's attention are supported by this philosophical school.

\section{References}

Biyabangard, E. (2005). Educational psychology. Tehran: Edit.

Vajargag, F. K. (2009). Fundamental concepts and principles of curriculum planning. Tehran: Baal.

Gutek, G. L. (2005). Philosophical schools and educational opinions. Translated by Mohammad Jafar Paak Seresht. Tehran: Samt.

Joyce, B., Weil, M., \& Calhoun, E. (2009). Teaching models 2004. Translated by Mohammad Reza Behrangi. Tehran: Kamal Tarbiyat.

Maleki, H. (2001). Curriculum planning. Tehran: Madrese

Mehrmohammadi, M. (2009). Curriculum, views, approaches, and scopes. Tehran: Samt.

Naler, J. F. (1998). Becoming familiar with education. Translated by Fereydoon Bazargan Dilmaghi. Tehran. Samt.

Shoarinejad, A. A. (2004). Philosophy of education. Tehran: Amirkabir. 